\title{
Estimation of the power electronic converter lifetime in fully rated converter wind turbine for onshore and offshore wind farms
}

\author{
${\text { K Givaki* }{ }^{*} \text { M Parker }{ }^{\dagger}, \text { P Jamieson }}^{+}$ \\ ${ }^{*}$ CDT for Wind Energy Systems, Uni. of Strathclyde, Glasgow, UK.E-mail: k.givaki@strath.ac.uk \\ ${ }^{\dagger}$ CDT for Wind Energy Systems, Uni. of Strathclyde, Glasgow,UK.E-mail: max.parker@strath.ac.uk \\ ${ }^{+}$CDT for Wind Energy Systems, Uni. of Strathclyde, Glasgow, UK. Email: peter.jamieson@eee.strath.ac.uk
}

\begin{abstract}
A comparison has been made of the converter lifetime for a 3MW fully rated converter horizontal axis wind turbine located onshore and offshore. Simulated torque and speed of the turbine shaft were used to calculate voltage and current time series, that was used to calculate the junction temperatures of the diode and IGBT in the generatorside converter by a thermal-electrical model. A rainflow counting algorithm was applied to the junction temperature in combination with an empirical model of the lifetime estimation, to calculate the lifetime of the power electronic modules in the turbine. The number of parallel modules for each location to achieve 20 years life time has also been found. Simulations show the lifetime consumption rate of the diode and IGBT is decreased exponentially by increasing number of parallel modules, lowering the average temperature. The offshore wind turbine has a higher lifetime consumption rate, requiring a slightly higher converter rating to achieve a 20 -year lifetime, but this difference is small, and both turbines will use the same number of modules.
\end{abstract}

\section{Introduction}

The worldwide installed capacity of wind turbines is increasing every day, with the EU governments intending to increase the share of renewable energies of the total energy production to $20 \%$ by 2020 [1]. In the UK, in accordance with EU policies, the share of the renewables in the overall energy production should increase to $15 \%$ by 2020 [2]. One of the best renewable resources in the UK is wind energy [3,4]; therefore investments in wind energy technologies are increasing rapidly. Mean wind speed offshore is much higher than onshore, so there is significant interest in constructing offshore windfarms. The availability of the turbines onshore is higher than the offshore wind turbines, mainly due to the accessibility of the wind turbine and the environmental conditions in the offshore sites [5].

One of the most important causes of failure in variable speed wind turbines is the converter, and the failure rate is increased for larger machines [6].

In modern wind turbines, converters use Insulated Gate Bipolar Transistors (IGBTs) as the switching devices. The IGBTs are available with two different packaging types, shown in Figure 1. Selection of the type of IGBT package depends on voltage level of the application. In the wind turbines, because of their low voltage level $(<1000)$, usually the conventional modules are used; on the other hand, for medium voltage ( $>1000)$ applications, presspack modules are usually the best solution. Fault conditions for these two different types of IGBT are different. The failure mode in the classic presspack module is the short circuit due to a turn off failure in the IGBT, while in the conventional modules open circuit at short times and accordingly a short circuit is the main failure mode [7]. It should be mentioned that presspack IGBTs are designed to fail in short circuit, but conventional modules can fail in both
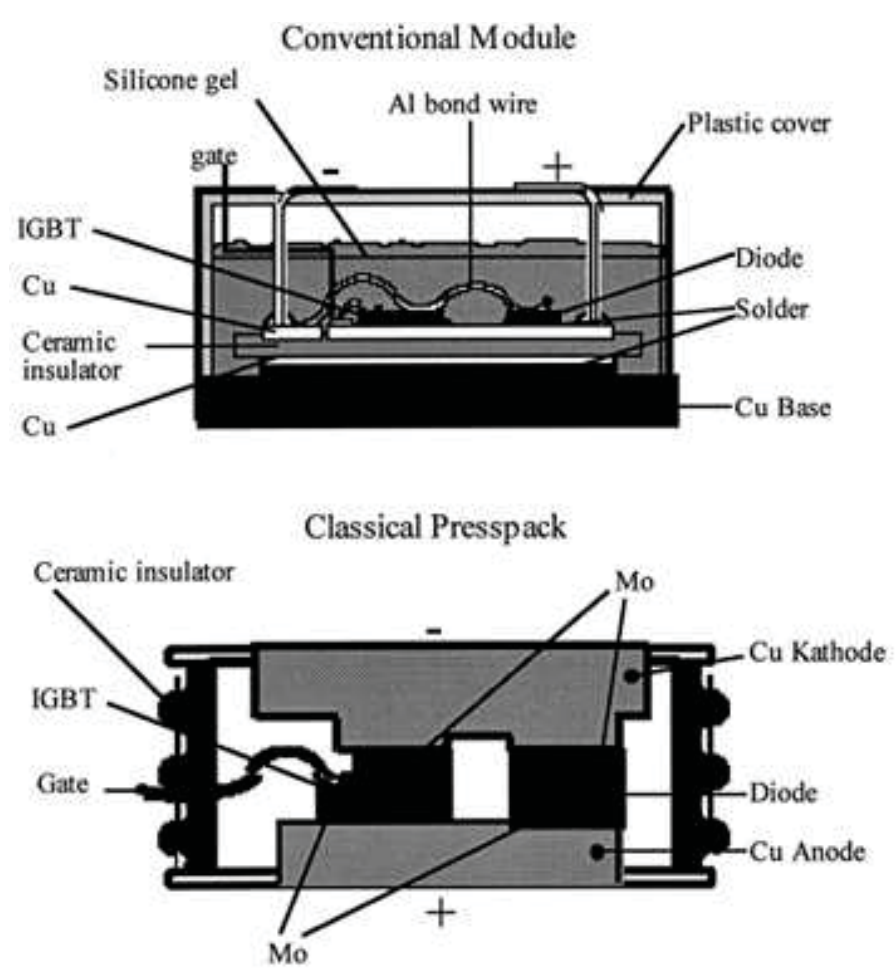

Figure 1. Different types of IGBT modules [7] .

open and short circuit.

Power electronics failures can be categorized into two failure mechanism groups: chip related and package related failures. Packing related failures are the most frequent failures that occur in the power electronic devices. This failure mechanism is mainly due to the difference in coefficients of thermal expan- 
sion (CTE) of the different parts of chip and packaging, which leads to thermo-mechanical stress on the packaging [8]. Overall, fatigue on the solder due to the thermal cycling is the main reason for the failure in the power modules. In the horizontal axis wind turbines (HAWTs), alternating current that causes pulsating loss in the IGBT and diode is one of the reasons for the thermal cycling as well as the variation of the wind speed, which leads to variation of the converter load and hence temperature due to power losses.

As previously mentioned, the wind speed in the offshore sites is higher than in the onshore sites, so the trend of industry is to build new offshore wind farms. On the other hand, the higher wind speeds will cause higher stress on the wind turbine. Furthermore, wind turbulence will cause huge fatigue loading on the wind turbine [9]. The other difference between onshore and offshore wind conditions is the lower turbulence intensity in the offshore sites compared to the onshore [9].

Following this introduction, the model that has been used for lifetime simulation will be introduced; in section 3 simulation methodology will be presented. Then the results of the simulations will be presented in section 4 . Finally section 5 will conclude this paper.

\section{Model design}

In the wind power spectrum, there is a spectral gap in the wind for the frequency of 1 to 10 cycle per hour (period of around 10 minutes to 1 hour) [10], so in the wind turbine analysis, it can be assumed that wind speed in this period (period of around 10 minutes to 1 hour) is uniform. Therefore, the converter lifetime will be calculated based on a dynamic model using 10minute wind speed time series with several different average wind speeds. The average wind speeds are determined using a binning process, where the wind speeds between cut-in and cut-out speed are separated to different bins with a 10 minute mean speed value representing each bin. For each wind speed bin, a wind speed time series is generated based on the mean wind speed and the turbulence intensity, and this is used in a dynamic model to find the level converter degradation at that wind speed. Other previous works $[11,12]$, that calculate the power electronic lifetime in the wind turbines, do not take into account wind speed variations within the bins.

Figure 2 shows the structure of the model that used in this paper. A time series of drivetrain torque and rotor speed for each wind speed bin will be the output of the Turbine model. The generator model will produce the current and voltage for one phase from the given torque and speed values, which are used in the converter loss model to calculate the conduction and switching losses. Device temperatures will be obtained by the thermal model and from the results of the thermal losses. Then, the lifetime calculation model will calculate the lifetime of the switching devices from the temperature time series. Overall lifetime will be obtained by combining the lifetime for each wind speed bin based on the probability of the average wind speed being within that bin.

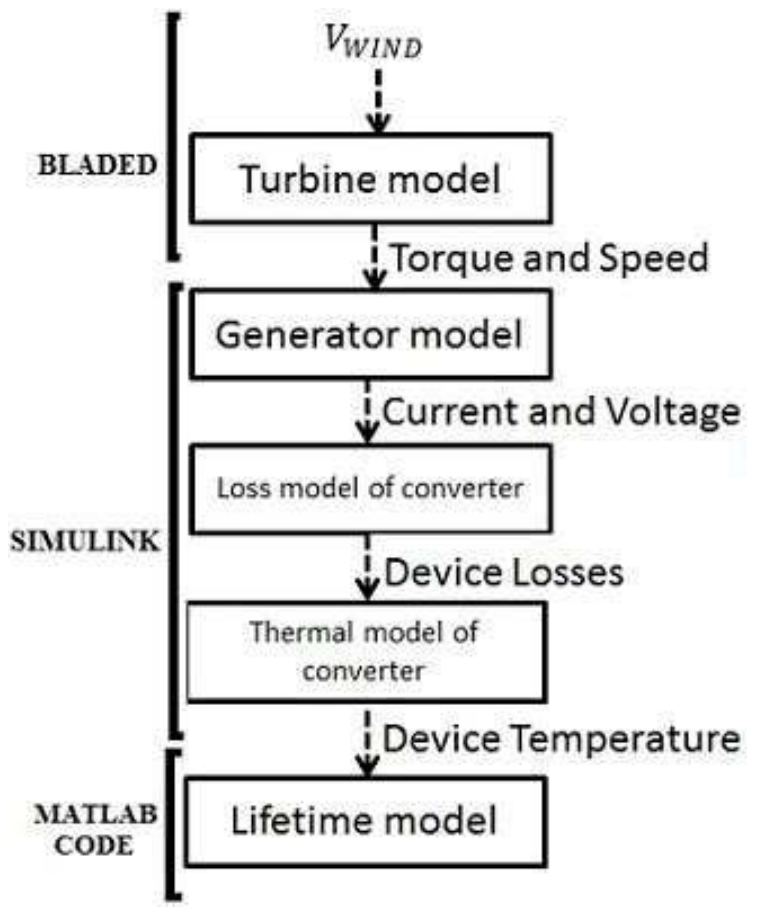

Figure 2. Structure of the model.

\subsection{Turbine model}

The rating of the turbine that was used in this study is $3 \mathrm{MW}$. Below rated wind speeds, the rotor speed is controlled to track the maximum power point. Once the rated wind speed is reached, pitch control will be used to keep the turbine at the 3MW output condition.

The specifications of the turbine are presented in Table 1. The output of the turbine block is the normalized torque and rotor speed, based on the turbine's rated torque and rotor speed.

Table 1. Wind turbine specification.

\begin{tabular}{|l|c|}
\hline Type & HAWT, Up Wind, Variable Speed \\
\hline Number of blades & 3 \\
\hline Power rating & $3 \mathrm{MW}$ \\
\hline Maximum speed & $1.50795 \mathrm{rad} / \mathrm{s}$ at low speed shaft \\
\hline Rated speed & $11.5 \mathrm{~m} / \mathrm{s}$ \\
\hline Speed range & $3-25 \mathrm{~m} / \mathrm{s}$ \\
\hline
\end{tabular}

\subsection{Generator and converter model}

A high speed permanent magnet generator has been used in this study. The output frequency of the generator $50 \mathrm{~Hz}$ and the per unit reactance is 0.4 . For simplicity, generator and gearbox losses have been ignored. Also gearbox ratio was set in the way to give rated generator speed at the rated turbine shaft speed. In this paper, only the generator-side converter was studied. To minimise the converter rating, the magnitude of the voltage of generator terminals was controlled to be equal to the EMF [13]. 


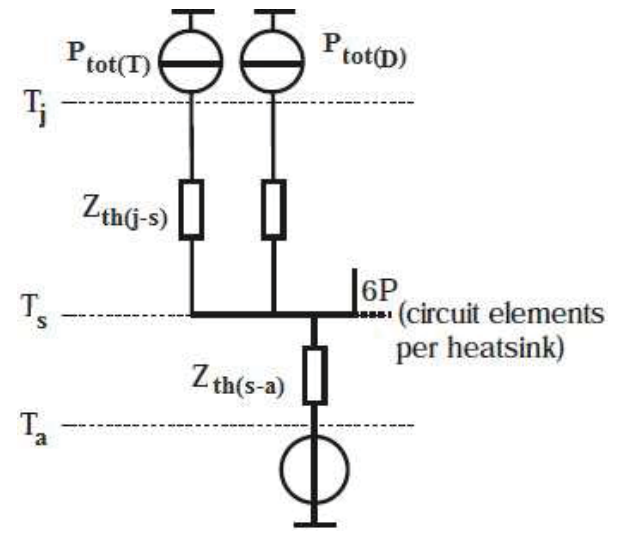

Figure 3. Thermal model of converter [14].

The rated voltage of the generator-side converter is $690 \mathrm{~V}$ and the DC-Link voltage is $1300 \mathrm{~V}$. In addition, the converter is selected to be based on an integrated power module (IPM) commonly used in wind turbine converters. The number of parallel IPMs can be changed in this model to test the impact of different converter ratings.

\subsection{Loss model of converter}

A conventional pulse width modulation (PWM) system, with third harmonic injection has been used to modulate the converter, with a switching frequency of $1 \mathrm{kHz}$. It is assumed that the frequency of the switching is high enough to have cause no ripple in the temperature of the switches, so to reduce simulation time the actual switching process has not been simulated in this study. On the other hand, the switching frequency is important to calculate the switching losses. The losses here were calculated using data provided by the manufacturer of the IPM [14]. It should be noted that the losses in the IPM are the combination of the switching and conduction losses.

To calculate losses with multiple parallel IPMs, the current in each IPM was divided by the number of parallel IPMs. Differences in power sharing between IPMs were ignored, and the impact on the switching loss of having parallel IPMs were also ignored. With multiple parallel devices, turn on and turn off of different modules may not happen at the same time and this will increase the losses. The impacts of the device temperature on the switching losses have also been ignored.

\subsection{Thermal model of converter}

The thermal model of the power electronic device is also given by the manufacturer and this model is based on the thermal equivalent circuit diagrams [14]. Figure 3 shows the thermal equivalent circuit for the device used in this study.

It is assumed that a water block with the water temperature of $40^{\circ} \mathrm{C}$ was the heatsink in this model. As seen in Figure 3, the diode and IGBT chips have their own thermal impedance related to the heatsink, $Z_{t h(j-s)}$, and both will see the same temperature in the heatsink, $T_{S}$. Also heatsink to ambient thermal impedance is also shown by $Z_{t h(s-a)}$. The thermal impedance between two points $\left(Z_{t h(x-y)}\right)$ can be obtained by the sum of 1 st order systems as can be seen in equation (1).

$$
Z_{t h(x-y)}(t)=\sum_{k=1}^{n} R_{j}\left(1-e^{\frac{-t}{\tau_{j}}}\right)
$$

In the above equation $R_{j}$ is the resistance of $j$ th element and $\tau_{j}$ is the time constant of element $j$. In the Simulink model, equation (1) is converted into the Laplace space (equation (2)) and the outputs of the transfer functions are summed.

$$
Z_{t h(x-y)}(S)=\sum_{k=1}^{n} \frac{R_{j}}{\tau_{j}} \frac{1}{S+\frac{1}{\tau_{j}}}
$$

Each IPM contains three parallel half-bridge circuits, each of which consists of multiple high and low side diode and IGBT chips. For this study, the individual thermal impedances in the IPM were aggregated to give the total impedances for the high and low side IGBTs and diodes and the heatsink.

\subsection{Lifetime model of the Converter}

There are two major methods of lifetime modeling for power electronic devices: empirical or analytical models, and physical models [15]. Analytical models describe the dependence of the number of cycles to failure on the parameters of temperature cycles i.e. amplitude, duration, frequency, mean value, dwell time, maximum and minimum temperature [15]. These models require some parameters that usually are provided by the device manufacturer. Physical modelling is the modelling of the physical process that will be the cause of the failure in the power electronic device. In these methods testing of the failure mode must be done to obtain accurate results [16].

An empirical formula (equation (3)) has been used for modeling of the lifetime of the power electronics devices in this paper. Formula (3) was introduced by the LESIT project [17].

$$
N_{f}=A \cdot \Delta T_{j}^{\alpha} \cdot e^{\frac{E_{a}}{k_{b} \cdot T_{j m}}}
$$

where $N_{f}$ represents the number of cycles to failure of the device, $\Delta T_{j}$ is the junction temperature thermal cycle amplitude and $T_{j m}$ represents the mean absolute junction temperature. $A, \alpha$ and $E_{a}$ are constant values provided by the power electronic module manufacturer. Also, $k_{b}$ represents Boltzman constant.

The above model is assumed to be descriptive only; that means it does not take into account the physical structure of the module and the actual failure mechanisms of crack growth and reconstruction; it should be noted that the model is somehow related to the physical characteristic of the device because $\Delta T_{j}$ will have influence on the plastic deformation and $T_{j m}$ is related to the material properties [17]. Formula (3) will give the results by considering the temperature level where the thermal cycling occurs; but other parameter will be influential in the results of the lifetime calculations e.g. pulse duration, angle of inclination, bond wire thickness, solder thickness and chip thickness. A more accurate and complicated model had been proposed [14], but was considered too difficult to implement in this study. 
A rainflow counting algorithm was used to split the diode and IGBT junction temperature time series into many thermal cycles with different amplitude and average temperature [18], and equation (3) used to find the lifetime for each cycle. The lifetimes were combined using Miners rule to find the lifetime for each wind speed bin based on the 10 minute time series. Miner's rule is given in equation (4),

$$
\sum_{i=1}^{m} \frac{n_{i}}{N_{i}}=C
$$

where for each cycle, $i$, of a given magnitude and average temperature, $n_{i}$ is the number of cycles and $N_{i}$ represents the number of cycles to failure. In addition, $C$ is a constant, with value of 1 usually used.

\section{Simulation methodology}

The operating range of the wind turbine is divided to many different bins, with $2 \mathrm{~m} / \mathrm{s}$ step for each bin. Then the simulation has been fin in each bin for different numbers of parallel IPMs and different wind profiles. As the wind speed and turbulence intensity in onshore sites are totally different from those in offshore sites, wind profiles have been chosen to represent wind conditions onshore and offshore. Simulations has been run for an offshore wind turbine by choosing a mean wind speed of $9 \mathrm{~m} / \mathrm{s}$ and wind turbulence level of $16 \%$ and for an onshore wind situation the turbulence level increased by $15 \%$ and mean wind speed has been selected at $7 \mathrm{~m} / \mathrm{s}$. Both wind profiles use the Weibull probability distribution. 10 minutes was simulated, and the simulation time was set to give 1 minute for the heatsink temperature to stabilize.

The turbine torque and speed time series for the different wind speeds and turbulences were produced in Bladed, and a Matlab script was used to load each time series, run the Simulink electro-thermal model and calculate the power electronics lifetime for each wind speed. The script then calculated the overall lifetime, and the process was repeated for different numbers of parallel IPMs.

\section{Simulation results}

Junction temperature of the IGBT and diode versus wind speed for different parallel modules ( 1 to 4 ) are shown in Figure 4 and Figure 5 respectively. As can be seen, with more parallel modules, the temperature of the device will be lower, due to the reduced current in each device. The average temperature of the diode junction is more than that in the IGBT junction. It should be noted that IPMs are designed to operate as an inverter, and the rating of the IGBT is higher than that of the diode in each module. Here the IPM is operating as rectifier, in which more current will be conducted by the diode, so the temperature of diodes will be higher the IGBTs.

The estimated lifetime of the diode and IGBT for different number of modules for both offshore and onshore locations are given in Table 2. It can be seen that the lifetime of the diode for the generator-side converter is less than the lifetime of IGBT with the same number of the parallel modules, which is consistent with the higher temperature in the diode. The number

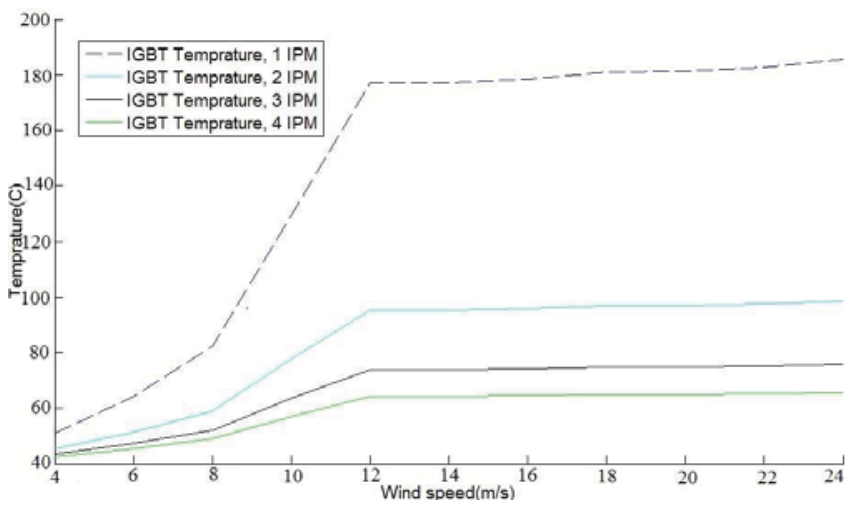

Figure 4. Temperature of IGBT junction for 1-4 IPMs for offshore wind turbine

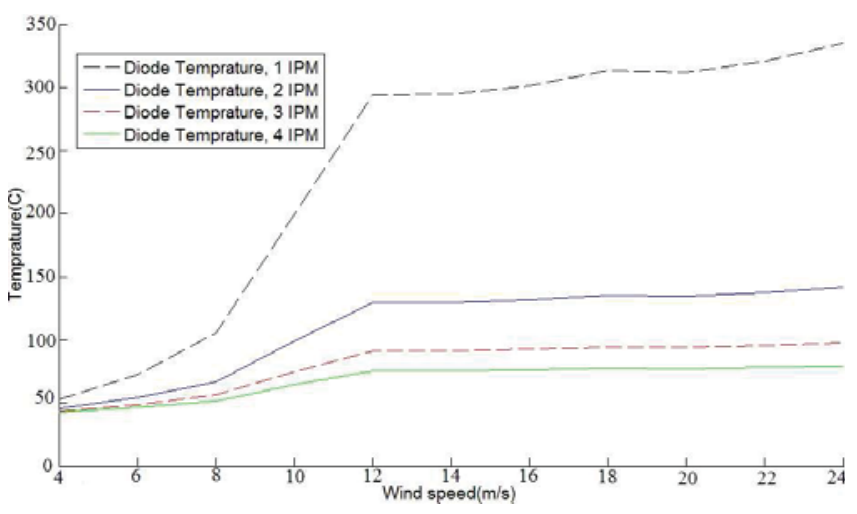

Figure 5. Temperature of diode junction for 1-4 IPMs for offshore wind turbine

of modules required to achieve 20 years converter lifetime was interpolated from the data, and is given in Table 3 and shown in Figure 6.

Table 2. Lifetime data for different number of parallel modules for both onshore and offshore.

\begin{tabular}{|c|c|c|}
\hline Number of Mod & IGBT lifetime(y) & diode lifetime(y) \\
\hline Offshore & \multicolumn{2}{|c|}{} \\
\hline 1 & 0.372 & 0.000043 \\
\hline 2 & 453.38 & 0.787 \\
\hline 3 & 11650 & 68.5 \\
\hline 4 & 89090 & 952 \\
\hline Onshore & & 0.00007 \\
\hline 1 & 0.63 & 0.722 \\
\hline 2 & 802 & 118.2 \\
\hline 3 & 26648 & 1716 \\
\hline 4 & 157456 & \\
\hline
\end{tabular}

Table 3. Required number of the modules for achieving 20 years lifetime.

\begin{tabular}{|c|c|c|}
\hline & Modls. for diode & Modls. for IGBT \\
\hline Offshore turbine & 2.725 & 1.561 \\
\hline Onshore turbine & 2.652 & 1.484 \\
\hline
\end{tabular}

The lifetime consumption rate of converter is determined as the probability of occurrence of a particular wind speed 


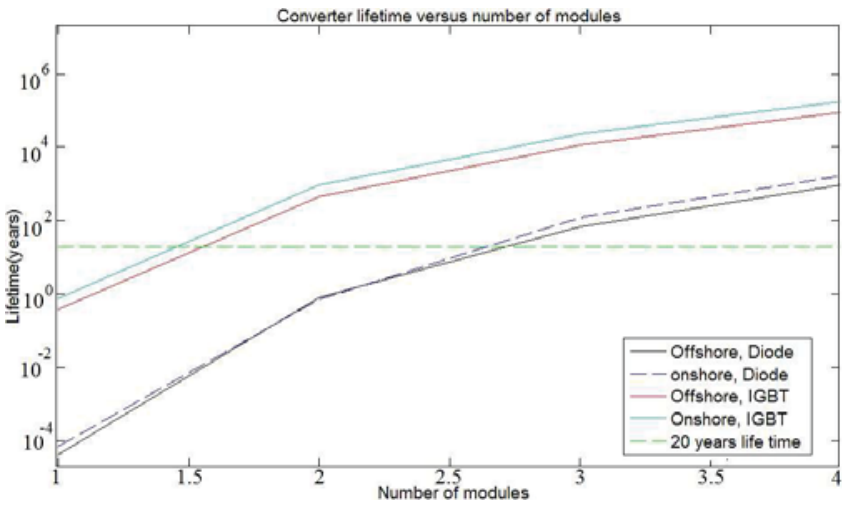

Figure 6. Temperature of IGBT junction for 1-4 IPMs for offshore wind turbine

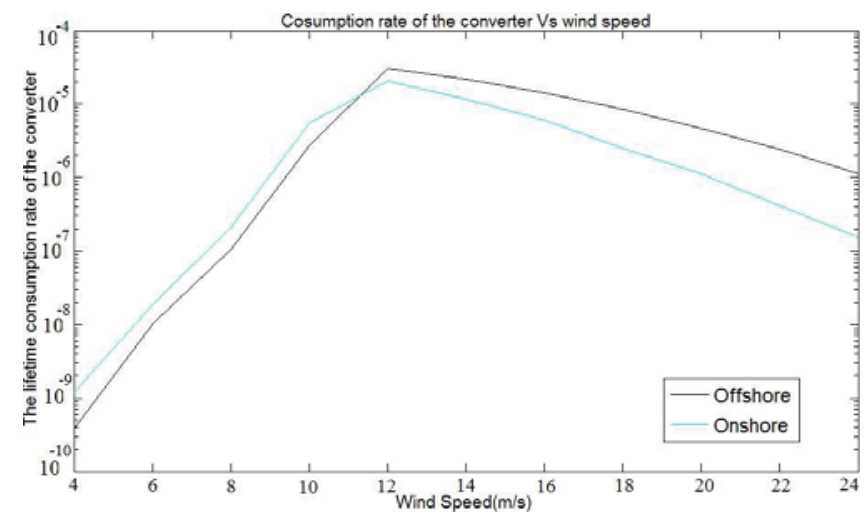

Figure 7. Lifetime consumption rate versus wind speed in offshore and onshore for 3 IPMs.

divided by the lifetime at that wind speed. Figure 7 shows the consumption rate of the IGBT versus wind speed in onshore and offshore wind turbines with three parallel modules.

As it can be seen in Figure 7, the consumption rate is highest around rated wind speed. This can be explained by the fluctuations in the power around the rated wind speed and switching in the control action from under rated to the above rated control actions. In addition the probability of the wind speed around the rated speed is relatively high, so the device consumption rate around the rated wind speed will be high. The consumption rate of the converter for a turbine that operates in a site with lower mean wind speed (onshore), is greater at low wind speeds (less than $10 \mathrm{~m} / \mathrm{s}$ ), than that for a turbine that operates in a site with high mean wind speed. This is due to the Weibull probability distribution, which has greater probability of lower wind speed for a low mean wind speed.

Figure 8 shows the lifetime consumption rate of the diode and IGBT for different number of parallel modules. From the figure, the lifetime consumption rate of the diode and IGBT is seen to be decreased exponentially by increasing the number of parallel modules.

\section{Conclusion}

Converter lifetime for a horizontal axis wind turbine for different wind conditions has been estimated. Two different mean

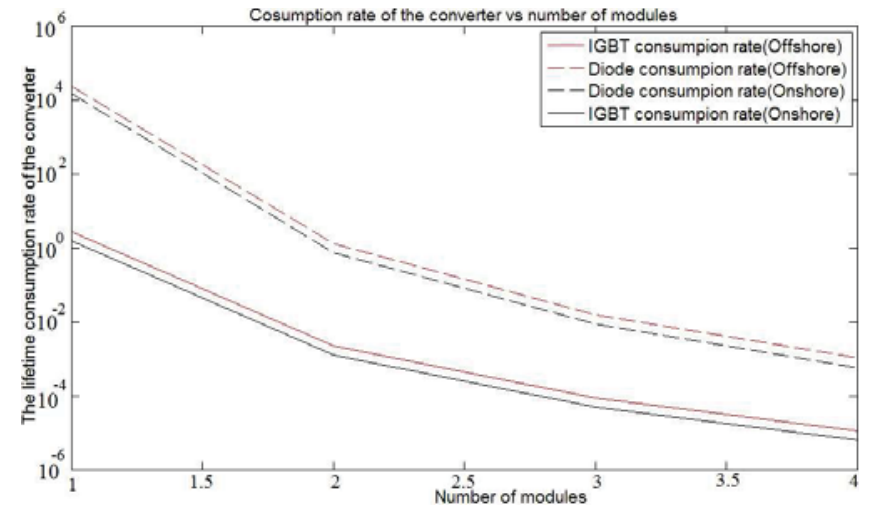

Figure 8. Lifetime consumption rate of IGBT and Diode versus the number of the parallel modules.

wind speeds and turbulence intensities with Weibull probability distribution, representing onshore and offshore sites, have been used. Converter lifetime has been estimated using a wind turbine model with generated wind data, an electro-thermal model and an empirical lifetime model at multiple average wind speeds within the operating range of the turbine, and the overall lifetime calculated. Around the rated wind speed the fluctuations of the torque and the high probability of wind speed occurrence will lead to the highest lifetime consumption rate of diode and IGBT. Simulations show the lifetime consumption rate of the diode and IGBT is decreased exponentially by increasing number of parallel modules, lowering the average temperature. The offshore wind turbine has a higher lifetime consumption rate, requiring a slightly higher converter rating to achieve a 20 -year lifetime, but this difference is small, and both turbines will use the same number of IPMs. Required converrter rating is determined by the lifetime of the diodes in the converter, as its consumption rate is much more higher than that in IGBTs due to the IPM being designed as an inverter rather than a rectifier, leading to higher diode loads.

One of the limitations in this study is the empirical model of lifetime estimation used. It is possible the empirical model is not an accurate model for the low amplitude, high number thermal cycles from the $\mathrm{AC}$ waveform. Therefore the best way to interpret the results is as a comparison between lifetimes in the onshore and offshore sites. Using a physical model can be more accurate, but the model would need to be calibrated with results from finite element simulations and accelerated lifetime testing.

\section{Acknowledgements}

This work has been funded by the EPSRC, project reference number EP/G037728/1.

\section{References}

[1] European Renewable Energy Council. "Renewable Energy Technology Roadmap 20\% by 2020", European Renewable Energy Council, Brusselsl, (2008). 
[2] Department of Energy and Climate Change. "UK Renewable Energy Roadmap", European Department of Energy and Climate Change, London, (2011).

[3] The World of Wind Atlases, "European wind resources at 50 metres", (1989),Available at http://www.windatlas.dk/Europe/landmap.html, Access date 2012-07-08.

[4] The World of Wind Atlases, "European wind resources over open sea", (1989),Available at http://www.windatlas.dk/europe/oceanmap.html, Access date 2012-07-08.

[5] G. Wilson, D. McMillan, G. Ault. "Modelling the effects of the environment on wind turbine failure modes using neural networks", International Conference on Sustainable Power Generation and Supply (SUPERGEN 2012), Hangzhou, (2012).

[6] F. Spinato, P. Tavner, G. J. W. van Bussel, E. Koutoulakos. "Reliability of wind turbine subassemblies" IET Renewable Power Generation, volume 3, no. 4, pp. 387-401, (2009).

[7] R. Zehringer, A. Stuck, T. Lang. "Material Requirements for High Voltage, High Power IGBT Devices" Solid-State Electronics, volume 42, no. 12, pp. 2139-2151, (1998).

[8] S. Yang, D. Xiang, A. Bryant, P. Mawby, L. Ran, P. Tavner. "Condition Monitoring for Device Reliability in Power Electronic Converters: A Review" IEEE Transactions on Power Electronics, volume 25, no. 11, pp. 2734-2752, (2010).

[9] T. Ishihara, A. Yamaguchi, M. Sarwar. "A Study of the Normal Turbulence Model in IEC 61400-1" Wind Engineering, volume 36, no. 6, pp. 759-766, (2012).

[10] I. Van der Hoven. "Power spectrum of horizontal wind speed in the frequency range from 0.0007 to 900 cycles per hour" Journal of Meteorology, volume 14, no. 2, pp. 160164, (1957).

[11] O. Senturk, S. Munk-Nielsen, R. Teodorescu, L. Helle. "Electrothermal modeling for junction temperature cycling-based lifetime prediction of a press-pack IGBT 3L-NPC-VSC applied to large wind turbines" IEEE Energy Conversion Congress and Exposition, Phoenix, (2011).

[12] F. Fuchs, A. Mertens. "Steady State Lifetime Estimation of the Power power semiconductors in the rotor side converter of a 2 MW DFIG wind turbine via power cycling capability analysis" 14th European Conference on Power Electronics and Applications (EPE 2011), Birmingham, (2011).

[13] A. Grauers, P. Kasinathan. "Force Density Limits in Low Speed PM Machines Due to Temperature and Reactance" IEEE Transaction on Energy Conversion, Volume 19, no. 3, pp. 518-525, (2004).

[14] A. Wintrich, U. Nicolai, W. Tursky, T. Reimann. "Application Manual Power Semiconductors" SEMIKRON International $\mathrm{GmbH}$, Nuremberg, (2010).

[15] I. Kovacevic, U. Drofenik, J. Kolar. "New Physical Model for Lifetime Estimation of Power Modules" International Power Electronics Conference (IPEC), Sapporo, (2010).

[16] C. Yin, H. Lu, M. Musallam, C. Bailey, C. Johnson. ”A Prognostic Assessment Method for Power Electronics Modules" 2nd Electronics System-Integration Technology Conference, (ESTC), Greenwich, 2008.

[17] M. Held, P. Jacob, G. Nicoletti, P. Scacco, M.-H. Poech. "Fast Power Cycling Test for IGBT Modules in Traction Application" International Conference on Power Electronics and Drive Systems, (1997).

[18] A, Nieslony. "Determination of fragments of multiaxial service loading strongly influencing the fatigue of machine components" Mechanical Systems and Signal Processing, Volume 23, no. 8, pp. 2712-2721, (2009). 